\title{
ANALISIS ADAPTASI KARAKTERISTIK VISUAL ARSITEKTUR MELAYU KAMPUNG TUA TANJUNG RIAU
}

\author{
${ }^{1}$ Gladies Imanda Utami Rangkuty, ${ }^{2}$ Niq'q Jean Carol, ${ }^{3}$ Elva Christina, ${ }^{4}$ Deviana, ${ }^{5}$ Angga \\ Setiawan Wilarso, ${ }^{6} \mathrm{Al}$ Ridho Wahyudi, ${ }^{7}$ Antony, ${ }^{8}$ Carlos Willyam, ${ }^{9}$ Hary Budhi Ardiansyah, \\ ${ }^{10}$ Wahyu Leonardi
}

1-10Universitas Internasional Batam, Batam, Indonesia gladies@uib.ac.id ${ }^{1}$

Informasi Naskah

Diterima: 22/06/2020; Disetujui terbit: 29/12/2020; Diterbitkan: 29/12/2020; http://journal.uib.ac.id/index.php/iad

\begin{abstract}
ABSTRAK
Pertumbuhan dan perkembangan kota sering tidak sejalan dengan pemahaman dalam mempertahankan identitas bangunan sehingga dapat menghilangkan eksistensi arsitektur peninggalan suatu kawasan. Hal ini dapat dilihat dari adaptasi visual arsitektur Melayu di Kampung Tua Tanjung Riau, yang terdapat penduduk asli merupakan etnis Melayu. Perkembang yang semakin pesat serta mendatangkan banyak penduduk baru yang menyebabkan terjadiya akulturasi budaya. Memiliki sebutan Kampung Tua tidak menjamin bahwa daerah tersebut akan terhindar dari pengaruh perkembangan zaman. Tampak bahwa sebagian besar arsitektur pada Kampung Tua Tanjung Riau telah berkembang menjadi lebih modern, sehingga bangunan Melayu yang menjadi identitas kampung tersebut menghilang seiring berkembangnya zaman. Adaptasi Karakteristik visual arsitektur melayu dilakukan dengan tujuan dapat mengetahui karakteristik bangunan tradisional pada kawasan kampung tua yang masih mempertahankan karakteristik Melayu. Penelitian ini menggunakan metode kualitatif deskriptif dengan melihat kondisi eksisiting yang ada pada lokasi. Hasil pada penelitian ini membuktikan bahwa masih ada beberapa bangunan yang masih mempertahankan beberapa karakter visual Arsitektur Melayu yang terlihat dari elemen bangunan seperti tangga, struktur panggung, dinding dan atap.
\end{abstract}

Kata kunci: Kampung Tua, Karakter Visual, Arsitektur Melayu, Identitas

\section{ABSTRACT}

The growth and development of the city is often not in line with the understanding in maintaining the identity of the building so as to eliminate the architectural existence of the heritage of an area. This can be seen from the visual adaptation of Malay architecture in Kampung Tua Tanjung Riau, where the indigenous people are ethnic Malay. The rapid development and the addition of many new residents led to cultural acculturation. Having the title Kampung Tua does not guarantee that the area will be spared from the influence of the times. It appears that most of the architecture in Kampung Tua Tanjung Riau has developed into more modern, so that the Malay building that became the identity of the village disappeared with the development of the era. Adaptation Visual characteristics of Malay architecture is carried out with the aim of being able to know the characteristics of traditional buildings in the old village area that still retain Malay characteristics. This research uses descriptive qualitative method by looking at existing conditions at the location. The results of this study prove that there are still some buildings that still retain some visual character of Malay Architecture that can be seen from building elements such as stairs, stage structures, walls and roofs.

Keywords: Kampong Tua, Visual Character, Melayu Architecture, Identity 


\section{Pendahuluan}

Kampung Tua merupakan istilah yang hanya dapat kita temukan di Indonesia pada daerah yang penduduk aslinya adalah Suku Melayu, salah satunya Kota Batam. Dalam Peraturan Daerah Kota Batam tahun 2004-2014 dinyatakan bahwa Kampung Tua atau Perkampungan Tua merupakan Kawasan Cagar Budaya yang perlu dijaga serta dilestarikan keberadaannya untuk melindungi eksistensi, adat istiadat, budaya, arsitektur bangunan, pemakaman, dan lingkungan tempat tinggal penduduk asli Kota Batam yang telah terlebih dahulu dibangun sebelum tahun 1970 ketika Batam mulai dikembangkan (Putra, 2019).

Kampung Tua Tanjung Riau merupakan salah satu Perkampungan Tua yang diresmikan dan ditetapkan pada Sabtu, 11 Mei 2013 di lapangan sepak bola Gladi Bakar Jaya, Tanjung Riau dengan luas wilayah 43,67 hektar (Humas Batam, 2013). Namun, faktor perkembangan zaman yang sangat pesat mengakibatkan sulit ditemukannya bangunan yang masih berkarakteristik Arsitektur Melayu pada daerah tersebut. Sebagian besar bangunan yang tampak sudah bermateri dasar beton dan lebih modern. Tetapi karena merupakan kawasan permukiman pesisir menyebabkan masih ada bangunan pada daerah perbatasan hingga perairan masih berpanggung, yang merupakan salah satu karakteristik Arsitektur Melayu.

Dengan ditemukannya sebuah bangunan yang masih berpanggung di daratan pada Kampung Tua Tanjung Riau memunculkan pandangan yang baru tentang Karakteristik Arsitektur Melayu pada permukiman tersebut. Walaupun sudah dipengaruhi oleh perkembangan zaman, tetapi masih ada Karakteristik Visual yang tersisa pada bangunan tersebut. Permasalah yang dilihat adalah adaptasi visual bangunan Kampung Tua Tanjung Riau terhadap perkembangan Kota Batam. Penelitian ini bertujuan melestarikan karakter visual Arsitektur Melayu pada bangunan yang dapat ditemukan di Kampung Tua Tanjung Riau yang telah beradaptasi terhadap perkembangan zaman namun masih mempertahankan karakteristik Melayu.

\section{Tinjauan Pustaka}

\subsection{Adaptasi Arsitektur}

Adaptasi berasal dari bahasa latin ad, yang berarti untuk, dan adaptare, yang berarti menyesuaikan diri. Dalam konteks adaptasi bangunan, adaptasi menyebabkan adanya adjust yaitu menyesuaikan, reuse yang artinya penggunaan kembali atau upgrade yang berarti meningkatkan esensi sebuah bangunan agar menjadi sesuai dengan kondisi serta keperluan baru (Parliana, 2010). Menurut Ir. Tony Kunto Wibisono M.Sc, adaptasi merupakan suatu upaya atau intervensi dalam rangka pengelolahan dan pengendalian perbuahan atribut fisik dan fungsional bangunan yang sudah ada karena bangunan tersebut sudah tidak layak digunakan dan dimanfaatkan atau telah melewati usia ekonomis (Faoji, 2018).

\subsection{Karakter Visual}

Karakter visual adalah suatu atribut atau fitur yang membentuk serta membedakan sebuah individu terhadap individu lainnya atau dengan kelompok lainnya (Adenan, Budi, \& Wibowo, 2012). Maka, karakter visual arsitektur dapat dipahami sebagai ciri khas bangunan yang dapat dilihat dan membedakan sekelompok bangunan Arsitektur Melayu dengan kelompok bangunan lainnya.

\subsection{Arsitektur Melayu}

Menurut Firzal (Rangkuty \& Widyastuti, 2019), tipologi rumah tradisional Melayu pada umumnya berbentuk persegi panjang dan bentuk dasarnya berupa rumah panggung. 
Sebagian besar atap berupa rumah perabung lurus dimana pertengahan puncak atas disebut bubung Melayu atau belah bubung, perabung atap yang sejajar dengan jalan raja disebut rumah perabung panjang, sedangkan yang tidak sejajar disebut rumah perabung melintang. Atap bangunan Melayu yang curam disebut lipat pandan, sedangkan yang mendatar atau landai disebut lipat kajang. Tambahan atap yang diberikan pada bagian bawah atap disebut atap labu/atap layar/atap bersayap/atap bertinggam. Terdapat karakteristik rumah Arsitektur Melayu, yaitu sebagai berikut (Riau Berbagi, 2015):

\subsubsection{Bagian-Bagian Bangunan Arsitektur Melayu}

a. Tangga

Memiliki tiang tangga yang biasanya berbentuk segi empat atau bulat. Tangan tangga wajib dipasang secara sejajar dengan tiang tangga pada kiri kanan tangga dan terdapat hiasan berupa kisi-kisi larik atau papan tembus.

\section{b. Sistem Penghawaan Udara}

Pada umumnya pintu dan jendela dibuat berukuran besar dan tinggi dengan tujuan supaya sirkulasi udara lancar (Irwin Ramsyah, 2011). Ukuran pintu: lebar $60-100 \mathrm{~cm}$, tinggi $1.5-2 \mathrm{~m}$ (Mansyur, 2018). Jendela (tingkap/pelinguk) memiliki bentuk yang sama dengan pintu tetapi ukurannya lebih kecil dengan satu atau dua lembar daun jendela. Jendela dipasang kisi-kisi yang terbuat dari kayu berbentuk segi empat. Kisi-kisi berukuran: tinggi 80-90 cm (Mansyur, 2018). Lubang angin berbentuk segi delapan, bulat, dan pada rumah sederhana umumnya dibuat berbentuk segi empat.

\section{c. Atap}

Awalnya bahan utama yang digunakan berupa daun pinah dan daun rumbai, tetapi telah digantikan oleh seng.

\subsubsection{Bahan-Bahan Arsitektur Melayu}

Pada umumnya tiang, tangga, gelegar, bendul, dan rasuk terbuat dari kayu, akan tetapi ada juga yang menggunakan bambu untuk menggantikan fungsi kayu. Dinding dan lantai terbuat dari papan, sedangkan atap dibuat dengan menggunakan daun nipah dan daun rumbia dengan rotan sebagai pengikat atap rumah.

\section{Metode Penelitian}

Penelitian Kualitatif Deskriptif adalah penelitian yang bertujuan mengungkapkan suatu kejadian atau fakta, keadaan, fenomena, variabel dan keadaan yang terjadi ketika penelitian berlangsung dengan menyajikan fakta (Prasetyo, 2016).

Langkah-langkah yang diambil sehingga penelitian dapat mencapai tujuan:

1) Mempersiapkan dan mengkaji bahan pustaka;

2) Membagi lokasi penelitian menjadi 3 zona: daratan, perbatasan, dan perairan;

3) Mencari informan mengenai data penelitian;

4) Menjalin hubungan sosial dengan penduduk lokasi penelitian;

5) Mengumpulkan data di lapangan, berupa peta, Jotted Notes, catatan pribadi, foto ataupun rekaman;

6) Menganalisis serta mengembangkan hipotesis kerja;

7) Penyelesaian analisis dan penulisan laporan. 


\section{Hasil dan Pembahasan}

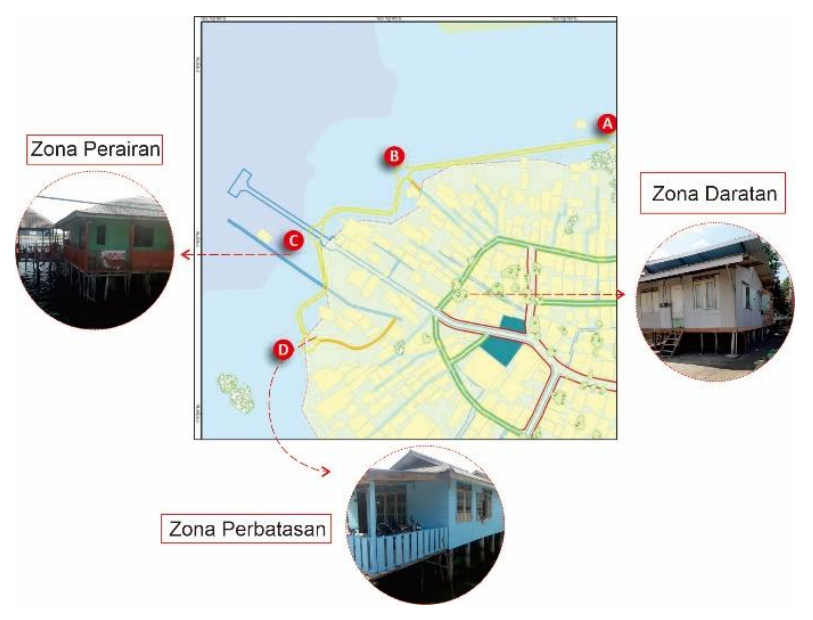

Gambar 1. Lokasi Penelitian

Sumber: Penulis, 2020

Berdasarkan proses penelitian, maka lokasi penelitian dibagi menjadi 3 zona:

\subsection{Zona Perairan}

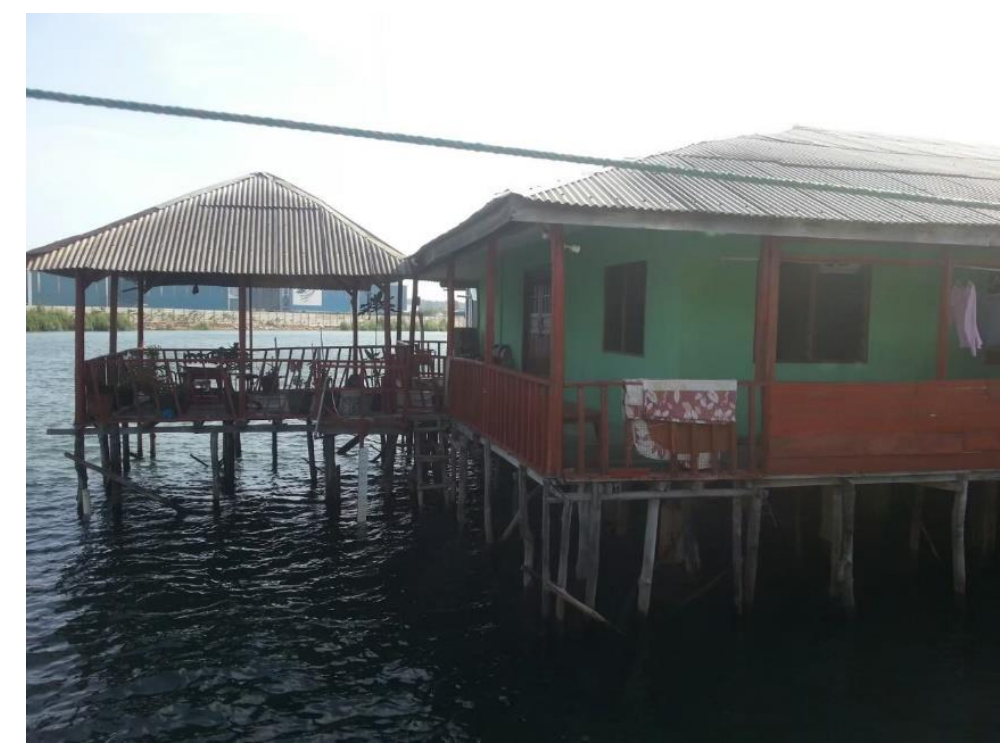

Gambar 2. Bangunan pada Zona Perairan Sumber: Penulis, 2020

Adaptasi bangunan terhadap lingkungan, karena berada pada daerah perairan menyebabkan bangunan yang berada pada zona tersebut masih berpanggung. Adapula bagian kaki bangunan yang menggunakan kayu sebagai bahan utama. Pada zona perairan ini, dinding bangunan sudah dibuat dengan bahan batu bata dengan atap berupa atap limas yang terbuat dari seng, dan jendela dua daun. Tidak terdapat tangga pada bangunan ini. Sebagian besar bangunan yang tepat berada pada dermaga utama memanfaatkan serambi sebagai ruang untuk menjalankan usaha (rumah makan). 


\subsection{Zona Perbatasan}

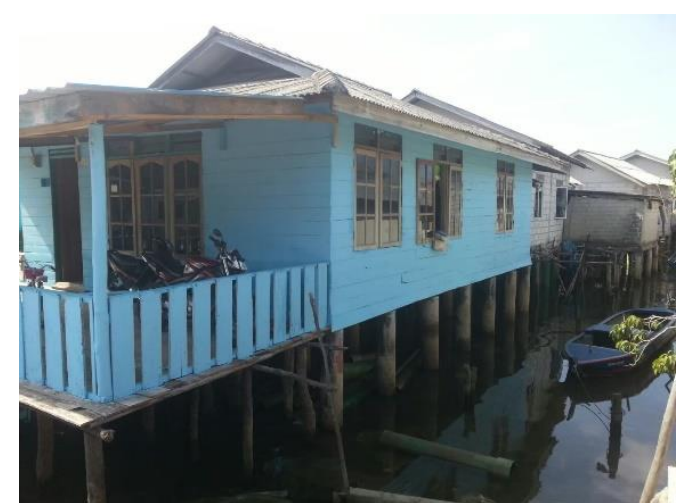

Gambar 3. Bangunan 1 Zona Perbatasan Sumber: Penulis, 2020

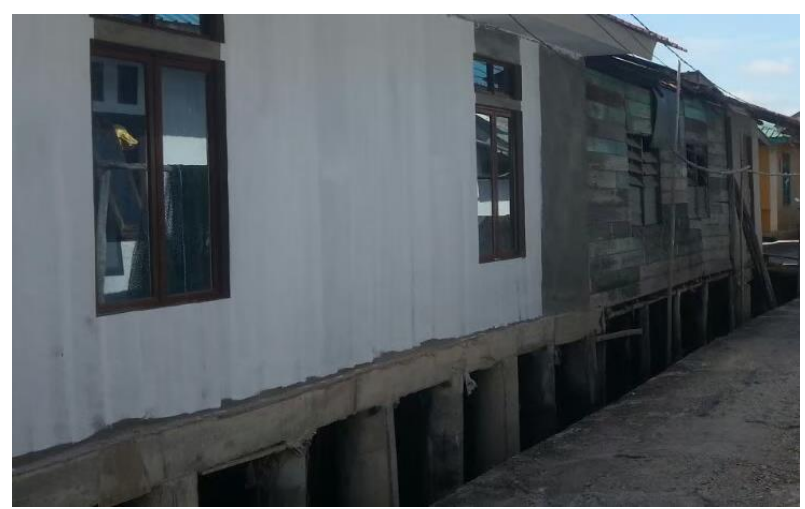

Gambar 4. Bangunan 2 Zona Perbatasan Sumber: Penulis, 2020

Hampir mendekati ciri yang dimiliki oleh bangunan pada zona perairan. Namun, sebagian besar kaki pada bangunan di zona perbatasan sudah berbahan dasar beton. Dinding masih terbuat dari kayu atau papan, dengan lubang angin berbentuk segi empat yang terletak diatas jendela. Atap pada zona perbatasan ini berupa atap lipat pandan.

\subsection{Zona Daratan}

Bangunan berpanggung yang masih utuh yang dapat ditemukan pada zona daratan hanya satu. Kaki pada bangunan ini masih terbuat dari kayu. Terdapat tangga yang berbentuk segi empat yang terbuat dari kayu tetapi tidak diberi tangan tangga. Dindingnya masih terbuat dari papan kayu dengan lubang angin berbentuk segi empat di atas setiap dua daun jendela. Atap berupa atap lipat kajang yang menggunakan seng sebagai penutup atap.

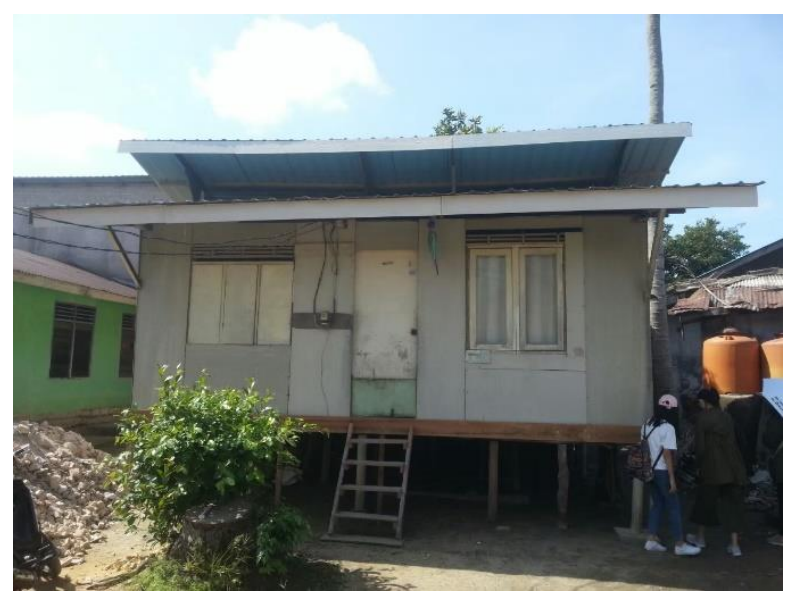

Gambar 5. Bangunan Zona Daratan

Sumber: Penulis, 2020 
Berikut adalah tabel hasil penelitian:

Tabel 1. Klasifikasi Bagian Bangunan

\begin{tabular}{|c|c|c|c|c|}
\hline No & Bagian-Bagian & Zona Perairan & Zona Perbatasan & Zona Daratan \\
\hline 1. & Gambar & & 7 form & \\
\hline 2. & Struktur & Berpanggung & Berpanggung & Berpanggung \\
\hline 3. & Tangga & Tidak ada & Tidak ada & Ada \\
\hline 4. & $\begin{array}{l}\text { Penghawaan } \\
\text { Udara }\end{array}$ & $\begin{array}{l}\text { - Terdapat pintu dari } \\
\text { kayu } \\
\text { - Jendela sudah } \\
\text { terbuat dari kaca } \\
\text { - Tidak terdapat } \\
\text { lubang angin di atas } \\
\text { jendela }\end{array}$ & $\begin{array}{l}\text { - Pintu dari kayu } \\
\text { - Jendela } \\
\text { perpaduan antara } \\
\text { kayu dan kaca } \\
\text { - Terdapat lubang } \\
\text { angin berbentuk } \\
\text { segi empat di atas } \\
\text { jendela }\end{array}$ & $\begin{array}{l}\text { - Pintu terbuat dari } \\
\text { papan } \\
\text { - Jendela terbuat } \\
\text { dari papan dan } \\
\text { kayu dan } \\
\text { terdapat kisi-kisi } \\
\text { - Terdapat lubang } \\
\text { angin berbentuk } \\
\text { segi empat di } \\
\text { atas jendela }\end{array}$ \\
\hline 5. & Dinding & Terbuat dari bata & $\begin{array}{l}\text { Terbuat dari bata } \\
\text { dan papan }\end{array}$ & $\begin{array}{c}\text { Terbuat dari papan } \\
\text { dan kayu }\end{array}$ \\
\hline 6. & Atap & $\begin{array}{l}\text { Atap limas dengan } \\
\text { penutup seng }\end{array}$ & $\begin{array}{l}\text { Atap lipat pandan } \\
\text { dengan penutup } \\
\text { seng }\end{array}$ & $\begin{array}{c}\text { Atap lipat kajang } \\
\text { dengan penutup } \\
\text { seng }\end{array}$ \\
\hline
\end{tabular}

Sumber: Penulis, 2020

\section{Kesimpulan}

Dari hasil penelitian dapat diambil kesimpulan bahwa perkembangan zaman membawa pandangan dan pola pikir baru terhadap penduduk Kampung Tua, dimana hal ini berdampak pada sisi arsitekturnya. Bangunan-bangunan di Kampung Tua seharusnya menunjukan Budaya Melayu yang memiliki karakter pribadi. Namun pada nyatanya, bangunan yang bercirikan Arsitektur Melayu mulai berkurang. Bahkan sangat sulit lagi untuk menemukan sebuah bangunan yang memenuhi karakteristik dari Arsitektur Melayu.

Dapat kita lihat pada hasil dan pembahasan, hanya terdapat satu bagunan berpanggung yang dapat ditemukan pada zona daratan yang memiliki karakter visual hampir menyerupai bangunan berarsitektur Melayu. Karakter-karakter yang masih bertahan tersebut telah berhasil beradaptasi terhadap perkembangan, baik dari segi bagian bangunan maupun bahan. Perubahan yang paling signifikan hanya tampak pada bahan penutup atap yang seharusnya berupa daun nipah dan daun rumbia, kini telah terbuat dari seng. Sedangkan bangunan pada zona perairan telah banyak mengalami perubahan hingga karakter visual Arsitektur Melayu tidak lagi tampak jelas pada bangunan tersebut. Karakter visual yang masih terlihat hanya pada strukturnya yang berpanggung karena berada di perairan.

Adaptasi bangunan memang diperlukan seperti yang telah dibahas oleh Parliana,2010, namun perlu disadari oleh seluruh masyarakat Indonesia, bahwa budaya sangatlah penting untuk menunjukan jati diri. Bangunan-bangunan di Kampung Tua yang masih menunjukan 
beberapa karakteristik arsitektur melayu harus dijaga dan dilindungi eksistensinya agar Kampung Tua tidak kehilangan identitas arsitekturnya.

\section{Daftar Pustaka}

Adenan, K., Budi, B. S., \& Wibowo, A. S. (2012, July). Karakter Visual Arsitektur Karya A.F. Aalbers di Bandung. Retrieved from Jurnal Lingkungan Binaan Indonesia Vol.1 No.1 Juli 2012: https://jlbi.iplbi.or.id/wp-content/uploads/2012/07/V1N1-p063-p074Karakter-Visual-Arsitektur-Karya-A.F.-Aalbers-di-Bandung-1930-1946.pdf

Faoji, S. (2018, March 22). Pengendalian Adaptasi Bangunan. Retrieved from Architecture.UII: https://architecture.uii.ac.id/news/pengendalian-adaptasi-bangunan/

Humas Batam. (2013, May 11). Masyarakat Tanjung Riau Gelar Syukuran dan Launching Kampung Tua. Retrieved from Mediacenter.Batam: https://mediacenter.batam.go.id/arsip/humas/index.html\%3Fp=22507.html

Irwin Ramsyah, S. (2011). Bentuk, Susunan, dan Pola Ruang Arsitektur Melayu Kalimantan Barat. Retrieved from Deposit Pustaka: https://www.kalbariana.web.id/bentuksusunan-dan-pola-ruang-arsitektur-melayu-kalimantan-barat/

Mansyur, M. (2018, September 30). Arsitektur Rumah Melayu Kayong. Retrieved from Slide Share: https://www.slideshare.net/MuhammadMansyur11/arsitektur-rumah-melayukayong

Parliana, D. (2010). Adaptasi Bentuk dan Fungsi secara Pragmatis pada Hunian Kampung. Jurnal Rekayasa, 1-12.

Prasetyo, A. (2016, September 7). Pengertian Penelitian Deskriptif Kualitatif. Retrieved from Linguistik Id: https://www.linguistikid.com/2016/09/pengertian-penelitian-deskriptifkualitatif.html

Putra, E. (2019, December 31). Mengenal Kampung Tua Batam. Retrieved from Antara Kepri: https://kepri.antaranews.com/berita/60967/mengenal-kampung-tua-batam

Rangkuty, G. I., \& Widyastuti, D. T. (2019). Tipologi Arsitektur Fasad Bangunan Pecinan Melayu Kasus: Jalan Perniagaan Kampung Cina Melayu Bagansiapiapi, Rokan Hilir,Riau. EE Conference Series 02.

Riau Berbagi. (2015). Rumah Tradisional Belah Bubung Asal Kepulauan Riau. Retrieved from Riau Berbagi: https://riauberbagi.blogspot.com/2015/12/rumah-belah-bubung-asalriau.html 